\title{
EVALUATION OF HYBRID MODELS FOR STATIC AND MULTISTAGE TRANSMISSION SYSTEM PLANNING
}

\author{
R. Romero*
}

M. Mantovani*

\author{
C. Rocha $^{\dagger}$
}

J. R. S. Mantovani*

\author{
${ }^{*}$ DEE-FEIS-UNESP \\ Av. Brasil Norte, 364 \\ CEP 15385-000 - Ilha Solteira SP \\ ${ }^{\dagger}$ CECE-UNIOESTE \\ Av. Tarquínio Joslin dos Santos, 1300 \\ CEP 85870-650 - Foz do Iguaçu PR
}

\section{RESUMO}

Neste trabalho é analisada a aplicação de algoritmos heurísticos para o Modelo Híbrido Linear - Hybrid Linear Model (HLM) - no problema de planejamento da expansão de sistemas de transmissão. O HLM é um modelo relaxado que ainda não foi suficientemente explorado. Assim, é realizada uma análise das características do modelo matemático e das técnicas de solução que podem ser usadas para resolver este tipo de modelo. O trabalho analisa em detalhes um algoritmo heurístico construtivo para o HLM e faz uma extensão da modelagem e da técnica de solução para o planejamento multi-estágio da expansão de sistemas de transmissão. Dentro deste contexto, também é realizada uma avaliação da qualidade das soluções encontradas pelo HLM e as possibilidades de aplicação deste modelo em planejamento de sistemas de transmissão. Finalmente, são apresentados testes com sistemas conhecidos na literatura especializada.

PALAVRAS-CHAVE: Modelos relaxados de otimização, pla- nejamento da expansão de redes, modelos híbridos, algoritmos heurísticos construtivos, planejamento multi-estágio.

\section{ABSTRACT}

This work analyses the application of heuristic algorithms in the transmission network expansion planning problem using the Hybrid Linear Model (HLM). The HLM is a relaxed model which still has not been fully explored. The work presents a detailed study of a constructive heuristic algorithm for the HLM and proposes an extension of the model and a solution technique for multi-stage planning. Quality evaluation of solutions found by HLM and the possibilities of application of the model for transmission system planning are also discussed. Finally, tests with the most known systems of the specialized literature are presented.

KEYWORDS: Optimization relaxed models, network expansion planning, hybrid models, constructive heuristic algorithms, multi-stage planning.

\footnotetext{
Artigo submetido em 24/02/2006

1a. Revisão em 21/08/2006

2a. Revisão em 05/01/2007

Aceito sob recomendação do Editor Associado

Prof. Carlos A. Castro
} 


\section{INTRODUCTION}

The main objective of the electric system transmission expansion plan is specify transmission lines and/or transformers that should be built in order for the system to operate in an adequate form in a specified planning horizon. Problem data are: base year topology, candidate circuits, generation and load data in the specified planning horizon, investments restrictions, etc. The planning solution specifies the location, the moment and the quantity of new equipaments. When static planning is under consideration there is a single planning horizon. Generalization of these concepts leads to the multi-stage planning with the splitting of the planning horizon into several stages. This work analyses two types of planning approaches with models from network synthesis applied for long-term expansion planning. Usually, topologies found for long-term planning are further analyzed using techniques of short-term planning such as AC power flow, stability analysis, among others, however our work relies only on issues related to the long-term planning.

The long-term transmission system expansion problem is usually represented by a mathematical model called DC model. The DC model is a non-linear mixed integer problem which is difficult to solve for large-scale systems. Others models that have been used are relaxed models such as the transportation model and hybrid models.

This work analyzes the hybrid linear model and proposes the use of constructive heuristics to solve it. More details of mathematical modeling can be found in Romero et alii (2002).

When the power grid is represented by the DC power flow model, the mathematical model of the transmission system expansion static planning problem is formulated as follows:

$$
\begin{aligned}
\text { Minv }= & \sum_{(i, j) \in \Omega} c_{i j} n_{i j} \\
\text { s.t. } & S f+g=d \\
& f_{i j}-\gamma_{i j}\left(n_{i j}^{0}+n_{i j}\right)\left(\theta_{i}-\theta_{j}\right)=0 \\
& \left|f_{i j}\right| \leq\left(n_{i j}^{0}+n_{i j}\right) \overline{f_{i j}} \\
& 0 \leq g \leq \bar{g} \\
& 0 \leq n_{i j} \leq \overline{n_{i j}} \\
& n_{i j} \text { integer, } f_{i j} \text { and } \theta_{j} \text { unbounded } \\
& (i, j) \in \Omega
\end{aligned}
$$

where $c_{i j}, \gamma_{i j}, n_{i j}, n_{i j}^{0}, f_{i j}$ and $\overline{f_{i j}}$ represent the cost of a circuit that can be added to right-of-way $\mathrm{i}-\mathrm{j}$, the susceptance of that circuit, the number of circuits added in right-of-way i$\mathrm{j}$, the number of circuits in the base case, the power flow and the corresponding maximum power flow in right-of-way $i-j$, respectively, v is the investment, $S$ is the transpose branch node incidence matrix of the system, $f$ is a vector with elements $f_{i j}, g$ is a vector with elements $g_{k}$ (generation in bus k) whose maximum value is $\bar{g}, \overline{n_{i j}}$ is the maximum number of circuits that can be added in righ-of-way $i-j$ and $\Omega$ is the set of all right-of-ways.

Constraint (2) represents the conservation of power in each node for the Kirchhoff's Current Law (KLC) constraint models in the equivalent DC network. Constraint (3) represents the Kirchhoff's Voltage Law (KVL). Moreover, these constraints are nonlinear.

In specialized literature many solution approaches for the transmission planning problem have been proposed. They can be joined into three groups: (1) constructive heuristic algorithms, (2) classic optimization algorithms such as Benders decomposition and branch-and-bound, (3) metaheuristics such as simulated annealing (SA), genetic algorithms (GA), tabu search (TS), GRASP, etc.

This work is part of a revision process of the mathematical modeling used in long-term transmission system planning as well as a revision of constructive heuristics used to solve them. We propose a detailed analysis of such algorithms, specially those that use the solution given by relaxed models after relaxing the integrality constraint of investment integer variables. That kind of strategy is more promising and can be easily extended to the multi-stage planning. This conclusion become clear when the best known constructive algorithm, the Garver's algorithm for the transportation model (Garver, 1970), was intensively analysed and improved in Romero et alii (2003). Therefore, the proposal represents a natural extension of the proposal presented in Romero et alii (2003) for the transportation model. In this case, the optimization technique for the hybrid model, which is an intermediate model between the transportation model and the DC model, has been developed.

In the next section the hybrid linear model is introduced and one type of constructive heuristic algorithm is presented. The solution technique is also extended to the multi-stage planning. Another aspect considered in the paper is the relevance of the relaxed models and constructive heuristic algorithms in the present context of the transmission network expansion problem. Finally, tests are presented with the systems referred to in specialized literature. 


\section{THE HYBRID LINEAR MODEL}

When the constraints (3) that represents the Kirchhoff's second law are relaxed in the DC model, the transportation model, which takes into account only the Kirchhoff's first Law and circuits operation constraints, is obtained. Any intermediary model between the DC model and the transportation model is called hybrid. It must be noticed that the transportation model is linear and the DC model is non-linear. Therefore, any model that considers only part of the constraints (3), represents a hybrid model. In this context, it is possible to formulate a hybrid linear model or a hybrid nonlinear model. This work considers the linear approach which is formulated as follows in (5).

In this formulation, $S^{0}$ is the transpose incidence nodebranch matrix formed by circuits and buses of base topology; $f^{0}$ is the vector of power flow through the circuits of the base topology with $f_{i j}^{0}$ elements; $S$ is the transpose incidence matrix of the entire system and $f$ is the vector of flows through added circuits with $f_{i j}$. elements The $\Omega_{0}$ symbol represents base case circuit indices and $\Omega$ the set with indices of all circuits.

$$
\begin{aligned}
\text { Minv }= & \sum_{(i, j) \in \Omega} c_{i j} n_{i j} \\
\text { s.t. } & S f+S^{0} f^{0}+g=d \\
& f_{i j}^{0}-\gamma_{i j} n_{i j}^{0}\left(\theta_{i}-\theta_{j}\right)=0 \quad \forall(i, j) \in \Omega_{0} \\
& \left|f_{i j}^{0}\right| \leq n_{i j}^{0} \overline{f_{i j}} \quad \forall(i, j) \in \Omega_{0} \\
& \left|f_{i j}^{0}\right| \leq n_{i j} \overline{f_{i j}} \quad \forall(i, j) \in \Omega \\
& 0 \leq g \leq \bar{g} \\
& 0 \leq n_{i j} \leq \overline{n_{i j}} \\
& n_{i j} \text { integer, } f_{i j}, f_{i j}^{0} \text { and } \theta_{j} \text { unbounded }
\end{aligned}
$$

In the hybrid model, flows that go through circuits which belong to the base case were represented separately from flows of added circuits. For example, consider that there is one circuit that connects path $\mathrm{i}-\mathrm{j}$ in the base case and the optimization process adds one circuit in paralel. Flows in the old circuit are represented by $f_{i j}^{0}$ and in the new circuit are represented by $f_{i j}$, which means that the values could be different among them. In this model, only circuits of the base topology must follow the KVL and this requirement is represented by constraint (7). When this condition is imposed, the hybrid model is linear.

The proposed HLM is a mixed integer linear problem, and it is possible to find solutions for systems with small and medium complexity using a branch-and-bound algorithm as presented in Haffner et alii (2001). However, in large scale problems with high complexity, the branch-and-bound algorithms demands a proibitive computation time. The advantage in using the HLM is that it is easier to solve than the DC model but the solution can be far from the DC model's optimal solution. However, the infeasibilities tend to be less than those found by the transportation model.

The HLM can be extended to the multi-stage planning applying the same strategy introduced in Romero et alii (2003). In this case, an expansion investment plan should be determined for the referred base year. Considering an annual discount rate of $I$, the present values of the investment costs and operation for the $t_{0}$ base year, with a horizon of $T$ years, are the following:

$$
\begin{array}{r}
c(x)=\frac{c_{1}(x)}{(1+I)^{t_{1}-t_{0}}}+\frac{c_{2}(x)}{(1+I)^{t_{2}-t_{0}}}+\ldots+\frac{c_{T}(x)}{(1+I)^{t_{T}-t_{0}}} \\
=\delta_{i n v}^{1} c_{1}(x)+\delta_{i n v}^{2} c_{2}(x)+\ldots+\delta_{i n v}^{T} c_{T}(x)
\end{array}
$$

where

$$
\delta_{i n v}^{t}=1 /(1+I)^{t_{t}-t_{0}}
$$

Using the relation above, the multi-stage planning for the hybrid model presents the formulation (12), show in the next page.

In this formulation, $\mathrm{v}$ is the present value of the expansion cost of the system, $\delta_{i n v}^{t}$ is the discount factor for determining the present investment value in stage $t$. Other variables are the same as static planning with the addition of index $t$, which indicates the planning stage. It must be observed that constraints (13) and (14) are the only constraints that relate different planning stages. These constraints do not allow decoupling of the multi-stage planning into $t$ independent problems. 


$$
\begin{aligned}
\text { Minv } v & \sum_{t=1}^{T}\left[\delta_{i n v}^{t} \sum_{(i, j)} c_{i j} n_{i j}^{t}\right] \\
\text { s.t. } & S^{t} f^{t}+S^{0} f^{0 t}+g^{t}=d^{t} \\
& f_{i j}^{0 t}-\gamma_{i j} n_{i j}^{0}\left(\theta_{i}^{t}-\theta_{j}^{t}\right)=0 \\
& \left|f_{i j}^{0 t}\right| \leq n_{i j}^{0} \overline{f_{i j}} \\
& \left|f_{i j}^{t}\right| \leq\left(\sum_{t=1}^{T} n_{i j}^{t}\right) \overline{f_{i j}} \\
& 0 \leq g^{t} \leq \overline{g^{t}} \\
& 0 \leq n_{i j}^{t} \leq \overline{n_{i j}^{t}} \\
& \sum_{t=1}^{T} n_{i j}^{t} \leq \overline{n_{i j}} \\
& n_{i j}^{t} \text { integer } \\
& \theta_{j}^{t} ; f_{i j}^{0 t} \text { and } f_{i j}^{t} \text { unbounded } \\
& \forall(i, j) \in \Omega, \quad t=1,2, \ldots, T
\end{aligned}
$$

\section{HEURISTIC ALGORITHM FOR THE HLM}

A constructive heuristic algorithm (CHA) is an iterative solver for finding a good quality solution of a complex program through a step-by-step process. For the transmission expansion problem, a new circuit, which can be a transmission line or a transformer is added at each step. The circuit is chosen by using a sensitivity indicator specified by the CHA. The sensitivity indicator represents the main feature by the CHA. The iterative process stops when a feasible solution is found and usually the solution is of good quality, i.e., there is no need for more circuit additions. The CHA is robust and usually rapidly converges to large scale and complex systems and these algorithms converges to good quality solutions only.

The sensitivity indicator is defined based on the optimal solution given by the hybrid linear model. It must be observed that if integrality constraints of investment variables are relaxed, i.e., $n_{i j} \geq 0$, the system (5) becomes a linear programmimg (LP) problem. The LP optimal solution provides optimal solution of the relaxed problem, i.e., considering the case that fractional circuits could be added. Furthermore, LP solution can be used to identify the best circuit to be included in the system. The sensitivity indicator is the power flow in the circuit with $n_{i j} \neq 0$ for the LP. The circuit to be added is identified by the following sensitivity indicator:

$$
I S=\max \left\{I S_{i j}=n_{i j} \overline{f_{i j}} ; \quad n_{i j} \neq 0\right\}
$$

where $\mathrm{n}_{i j}$ is the LP solution after relaxing the HLM's integrality constraint. The topology is updated at each CHA's step. The current topology is formed by circuits of base topology and from circuits added during the iterative process.

One of CHA's most favorable characteristics (which relaxes investment variable integrality constraints) is that the algorithm aims at finding the most important circuit in terms of investment and operation constraints. Thus, at each step that an integer $n_{i j}$ solution is found by LP, the algorithm finds the global optimal solution. The major drawback of that type of algorithm comes up at the end of the iterative process when almost all of the $n_{i j}$ given by the LP solution presents low fractional values. In this case, the algorithm becomes inefficient because decisions taken by comparing small values of $\mathrm{n}_{i j}$ can produce serious deviations when, in a practical situation, an integer number of circuits is introduced. This deviation is partially dealt with by incorporating an irrelevant circuit removal procedure after finishing the addition phase. Another option is to change the sensitivity indicator.

We can use Garver's fundamental idea applied to the transportation model to propose a novel constructive heuristic algorithm for the transmission system expansion static planning problem using the hybrid linear model. The Base Constructive Heuristic Algorithm assumes the following form:

\section{BCH Algorithm}

1. Assumes a base topology as current topology and use the HLM.

2. Solves an LP for the HLM using current topology. If LP indicates that the system is operating adequately with the added circuits, go to step 4 (a solution was found for HLM). Otherwise go to step 3.

3. Use the sensitivity indicator (15) to identify the most attractive circuit that should be added to the system. Update current topology with the chosen circuit and go to step 2.

4. List the added circuits in descent order of costs. Using an LP, verify wether a circuit removal keeps the system at an adequate operation point at each iteration. If the system operates adequately, remove the circuit. Otherwise, keep the circuit. Repeat the process, simulating each circuit removal until all circuits have been analyzed. The remaining added circuits represent CHA's solution.

In the proposed CHA there is a fundamental aspect related to the behavior of the added circuits in the base topology. The circuits added during the iterative process must follow KCL only or both KCL and KVL depending on the situation. If the 
objective is to find a solution fitted to the HLM presented in (5), the added circuits must follow the KCL only. However, if one intends to determine the final feasible solution for the DC model, all added circuits must follow both of Kirchhoff's laws. There is an intermediary case in which circuits added in paralel with the existing circuits in the base topology must follow both of Kirchhoff's law and those added in new paths must follow the First Law only. Therefore, there are three ways of implementing the CHA, which results in different final topologies with different algorithm performance. Whatever the case, an LP is solved at each iteration. This work analyzes only one algorithm and the first and third option are analyzed in another paper.

\subsection{Modified Algorithm for the Hybrid Lin- ear Model}

The objective of the modified algorithm is to find a more restrictive topology than HLM. As a consequence, topologies found by the algorithm should be more expensive than the HLM optimal solution. Circuits added in parallel to the existing ones during the iterative process must follow both of the Kirchhoff's circuit laws. Circuits added in new paths follow the KCL only. The advantage of using this optimization strategy relies on the fact that the final solution presents less unfeasibilities when tested in the DC model. This strategy partially preserves performance and consistency of the algorithm. The circuits that follow only KCL have an excellent performance. However, circuits added in parallel considering the indication based only on the KCL may not present good performance when added in parallel to an existing circuit because in this situation both laws must be followed.

In the algorithm, the LP has the mathematical formulation of (16). The circuits added during the iterative process are stored in different sets. Consequently, if the selected circuit corresponds to path $(\mathrm{i}, \mathrm{j}) \in \Omega_{0}$, then an element of $n_{i j}^{0}$ is updated, otherwise, an element of $n_{i j}^{1}$ is updated. For this reason, $\Omega_{1}$ represents the set of new paths added by addition of new circuits during the iterative process.

$$
\begin{aligned}
\text { Minv }= & \sum_{(i j) \in \Omega} c_{i j} n_{i j} \\
\text { s.t. } & S f+S^{0} f^{0}+S^{1} f^{1}+g=d \\
& f_{i j}^{0}-\gamma_{i j} n_{i j}^{0}\left(\theta_{i}-\theta_{j}\right)=0 \quad \forall(i, j) \in \Omega_{0} \\
& \left|f_{i j}^{0}\right| \leq n_{i j}^{0} \overline{f_{i j}} \quad \forall(i, j) \in \Omega_{0} \\
& \left|f_{i j}^{1}\right| \leq n_{i j}^{1} \overline{f_{i j}} \quad \forall(i, j) \in \Omega_{1} \\
& \left|f_{i j}\right| \leq n_{i j} \overline{f_{i j}} \quad \forall(i, j) \in \Omega \\
& 0 \leq g \leq \bar{g} \\
& 0 \leq n_{i j} \leq \overline{n_{i j}} ; \quad n_{i j} \geq 0 \\
& f_{i j}^{0} ; f_{i j}^{1}, f_{i j} \text { and } \theta_{j} \text { unbounded }
\end{aligned}
$$

Another theme related to algorithm is the possibility of exchanging the sensitivity indicator. The sensitivity indicator can be substituted or changed by using other proposals given by the LP corresponding solution. Two alternatives are: (1) After solving the first LP corresponding, add the integer part of $n_{i j}$ for all circuits with $n_{i j} \geq 1$ and continue the process as usual; (2) At each step, add the circuit with the largest $n_{i j}$. These modifications lead to slightly different algorithms and for large and complex systems they will provide different solutions.

\section{HEURISTIC ALGORITHM FOR THE MULTI-STAGE PLANNING}

The constructive heuristic algorithm for the static planning can be extended to the multi-stage planning using the same approach for the transportation model presented in Romero et alii (2003). In multi-stage planning, the planning problem for different stages must be solved in an integrated way. In this section, an extension of the previous CHA to the multistage planning, is presented. The critical point of a CHA for the multi-stage planning is the choice of sensitivity indicator. The proposed CHA for multi-stage planning using HLM presents the following form:

1. Consider base topology as current topology and use the hybrid linear model. Make current stage $\mathrm{k}=1$.

2. Solve the LP corresponding problem (12) for current topology. If $n_{i j}^{k}=0 \forall(\mathrm{i}, \mathrm{j}) \in \Omega$ then the addition phase in stage $\mathrm{k}$ is over. If a local search procedure must be implemented, go to step 4. Otherwise, go to step 3.

3. Use a sensitivity indicator to find the most attractive circuit in stage k. Update current topology with chosen circuit and go to step 2 . 
4. Execute step 4 of the $\mathrm{BCH}$ algorithm for stage $\mathrm{k}$. Thus, those circuits which are not removed will represent the solution to stage k. Go to step 5.

5. Update $\mathrm{k}=\mathrm{k}+1$ and go to step 2 .

In step 2, the algorithm solves an LP for current topology. The LP is slightly different from problem (12) because of the addition, which must be taken into account separately. If the modified algorithm for the hybrid model is used in step 2 of the algorithm, the LP becomes:

$$
\begin{aligned}
\text { Minv }= & \sum_{t=1}^{T}\left[\delta_{i n v}^{t} \sum_{(i, j)} c_{i j} n_{i j}^{t}\right] \\
\text { s.t. } & S^{0} f^{0 t}+S^{t} f^{t}+S^{1 t} f^{1 t}+g^{t}=d^{t} \\
& f_{i j}^{0 t}-\gamma_{i j} n_{i j}^{0}\left(\theta_{i}^{t}-\theta_{j}^{t}\right)=0 \\
& \left|f_{i j}^{0 t}\right| \leq\left(n_{i j}^{0}+\sum_{t=1}^{T} n_{i j}^{0 t}\right) \overline{f_{i j}} ; \quad \forall(i, j) \in \Omega_{0} \\
& \left|f_{i j}^{1 t}\right| \leq\left[\sum_{t=1}^{T} n_{i j}^{1 t}\right] \overline{f_{i j}} ; \quad \forall(i, j) \in \Omega_{1 t} \\
& \left|f_{i j}^{t}\right| \leq n_{i j}^{t} \overline{f_{i j}} \\
& 0 \leq g^{t} \leq \overline{g^{t}} \\
& 0 \leq n_{i j}^{t} \leq \overline{n_{i j}^{t}} \\
& \sum_{t=1}^{T} n_{i j}^{t} \leq \overline{n_{i j}} \\
& n_{i j}^{t} \geq 0 \\
& \theta_{k}^{t}, f_{i j}^{0 t} ; f_{i j}^{1 t} \text { and }, f_{i j}^{t} \text { unbounded } \\
& \forall(i, j) \in \Omega \quad t=1,2, \ldots, T .
\end{aligned}
$$

where $n_{i j}^{1 t}$ and $n_{i j}^{0 t}$ represent circuits inserted in stage $t$ in new paths (not belonging to the base topology) and the circuits inserted in parallel paths with the base topology respectively. $\Omega_{1 t}$ represents the set of new paths in which new circuits have been added in stage $t$.

Step 2 has to be analyzed in detail considering two basic aspects: (1) the addition logic, and (2) the use of a sensitivity indicator. The problem that appears to be solved in the first place is the transmission capability of initial stages. In other words, the algorithm performs all necessary circuit additions in order to provide the first stage with adequate operation conditions, then goes to stage 2 , and so on, until the last stage is reached. This methodology represents the most logical one and was employed in Romero et alii (2003) due to the fact that the first added circuits work in the next stages, therefore they reduce the need for more investments in the following stages.

The proposed sensitivity indicator identifies the most attractive circuit in path $(\mathrm{i}, \mathrm{j})$ with $n_{i j} \neq 0$ in stage $\mathrm{k}$ as the circuit that carries the largest amount of power flow considering all circuits added by LP subroutine for all stages $\mathrm{t} \geq \mathrm{k}$. Consequently, for each path with $n_{i j}^{k} \neq 0, f_{i j}=f_{i j}^{k}+f_{i j}^{k+1}+\ldots+$ $f_{i j}^{T}$ can be found, where $f_{i j}^{k+1}$ is the power flow in path (i,j) in stage $\mathrm{k}+1$. All of these values become available through LP solution.

Other alternative formulations of CHA can be implemented for multi-stage planning. One of the options consists in performing a local optimization (step 4), after finishing the addition process in all stages. It must be observed that the circuit removal phase in the proposed CHA comes at the end of each planning stage. Another option is to change the sensitivity index. For example, in stage $\mathrm{k}$, the most interesting path could be a path with $n_{i j}^{k} \neq 0$ and with the largest value of $n_{i j}=$ $n_{i j}^{k}+n_{i j}^{k+1}+\ldots+n_{i j}^{T}$.

There are others CHAs employed in the transmission system planning that present good performance, some of them were presented in Villasana et alii, 1985; Monticelli et alii, 1982; Pereira and Pinto, 1985; Levi and Calovic, 1991; Dechamps and Jamoulle, 1980. These algorithms also can be extended to the multi-stage planning.

\section{TESTS WITH PROPOSED ALGORITHM}

The proposed algorithm was implemented using FORTRAN programming language and MINOS 5.3 was employed as an LP subroutine. Only two systems, which are known in specialized literature, were tested and partial results are presented in detail.

\subsection{Brazilian 46-Bus Southern System}

The southern system has 46 buses, 79 circuits and $6880 \mathrm{MW}$ of demand. The data consists of static planning (Romero et alii, 2003). For this system, the planning is considered with generation redispatch only.

The proposed algorithm must find the following topology:

Planning with an algorithm: $v=87,617,000$ US $\$$

\begin{tabular}{|l|l|l|l|}
\hline $\mathrm{n}_{19-21}=1$, & $\mathrm{n}_{20-23}=1$, & $\mathrm{n}_{20-21}=2$, & $\mathrm{n}_{42-43}=1$, \\
\hline $\mathrm{n}_{06-46}=1$, & $\mathrm{n}_{05-06}=1$ & & \\
\hline
\end{tabular}

The Table 1 presents the solution process through iterations. $v_{L P}$ is the investment given by LP and $v$ is the partial invest- 
ment resulted from additions provided by the program.

The sequence of circuits additions performed by modified hybrid algorithm shown in Table 1 is the following: $\mathrm{n}_{20-21}$, $\mathrm{n}_{42-43}, \mathrm{n}_{05-06}, \mathrm{n}_{06-46}, \mathrm{n}_{20-21}, \mathrm{n}_{05-06}, \mathrm{n}_{20-23}$ and $\mathrm{n}_{19-21}$. The algorithm converges after solving 16 LPs and removing one circuit $\mathrm{n}_{05-06}$ at phase 2 .

It should be noticed that the optimal solution for the analyzed system considering the DC model is of $v=72,780,000$ and $v=63,163,000$ for the hybrid model [1]. The optimal solution for the hybrid model is formed by circuits determined by algorithm (Table 1) except circuit $\mathrm{n}_{19-21}$.

Observing the results obtained by the modified hybrid algorithm, the following aspects have to be mentioned: (1) The modified algorithm cannot find the optimal solution of the hybrid model because circuits that are added in parallel to the existing ones must follow Kirchhoff's Second Law, (2) the algorithm performs optimal additions until iteration number 8 when only circuit $\mathrm{n}_{19-21}$ maintains value 0.016 , (3) additions executed until interation 8 are optimal for the hybrid linear model and for the DC model. Although an optimal solution for the hybrid linear model has been found, the algorithm indicates the need for a new circuit due to KVL, which must be followed, (4) in the last step there is an erroneous choice of a circuit indicated by LP, which has an insignificant value, and (5) finally, the final topology is feasible for the DC model.

\subsection{Brazilian North-Northeastern System}

The system has 87 buses, 183 circuits and 29748 MW of load for the entire planning horizon. The system data is in Ruben et alii (2002) and the available data allows planning without generation rescheduling and a multi-stage planning with two stages. The system is very complex and the optimal solution is unknown. 1998 is considered as the base year and Plan P1 in 2002, and Plan P2 in 2008. Consequently, the needed circuits for 2002 are considered as cost of 1998 (original values) and the needed circuits in 2008 are considered as being built in 2002 and their costs are updated for the base year. In tests the factor of discount used is $\mathrm{I}=10 \%$. Therefore, the costs for a transmission line added in $\mathrm{P} 2$ are multiplied by 0.683 .

Considering Plan P1 and Plan P2 separately, the modified hybrid algorithm finds the following topologies:
Table 1: Hybrid modified algorithm

\begin{tabular}{|c|c|c|c|}
\hline Iter & Addition by LP & $v_{L P}$ & $v$ \\
\hline 1 & $\begin{array}{l}\mathrm{n}_{13-18}=0.526, \\
\mathrm{n}_{20-21}=1.382, \\
\mathrm{n}_{42-43}=0.904, \\
\mathrm{n}_{06-46}=0.233, \\
\mathrm{n}_{25-32}=0.107, \\
\mathrm{n}_{24-25}=0.249, \\
\mathrm{n}_{05-06}=0.777\end{array}$ & 41018.3 & 0 \\
\hline 2 & $\begin{aligned} \mathrm{n}_{13-18} & =0.526, \\
\mathrm{n}_{20-21} & =0.382, \\
\mathrm{n}_{42-43} & =0.904, \\
\mathrm{n}_{06-46} & =0.233, \\
\mathrm{n}_{25-32} & =0.107, \\
\mathrm{n}_{24-25} & =0.249, \\
\mathrm{n}_{05-06} & =0.777\end{aligned}$ & 32840.3 & 8178 \\
\hline 3 & $\begin{aligned} \mathrm{n}_{13-18} & =0.544, \\
\mathrm{n}_{20-21} & =0.382 \\
\mathrm{n}_{06-46} & =0.231 \\
\mathrm{n}_{25-32} & =0.107 \\
\mathrm{n}_{24-25} & =0.249 \\
\mathrm{n}_{05-06} & =0.770\end{aligned}$ & 25420.4 & 16356 \\
\hline 4 & $\begin{array}{l}\mathrm{n}_{13-18}=0.332, \\
\mathrm{n}_{20-21}=0.382, \\
\mathrm{n}_{06-46}=0.300 \\
\mathrm{n}_{25-32}=0.075, \\
\mathrm{n}_{24-25}=0.249\end{array}$ & 17784.1 & 24534 \\
\hline 5 & $\begin{array}{l}\mathrm{n}_{20-21}=0.382 \\
\mathrm{n}_{19-25}=0.107 \\
\mathrm{n}_{24-25}=0.250 \\
\mathrm{n}_{05-06}=0.358\end{array}$ & 12135.9 & 40539 \\
\hline 6 & $\begin{aligned} \mathrm{n}_{25-32} & =0.075 \\
\mathrm{n}_{24-25} & =0.249 \\
\mathrm{n}_{05-06} & =0.252\end{aligned}$ & 8087.1 & 48717 \\
\hline 7 & $\begin{array}{l}\mathrm{n}_{20-23}=0.357 \\
\mathrm{n}_{24-25}=0.089\end{array}$ & 3727.0 & 58895 \\
\hline 8 & $\mathrm{n}_{19-21}=0.016$ & 521.1 & 63163 \\
\hline 9 & & 0 & 95795 \\
\hline & \multicolumn{2}{|c|}{$\begin{array}{c}\text { Remove one circuit of } \\
\mathrm{n}_{05-06}\end{array}$} & 87617 \\
\hline
\end{tabular}


Plan P1: $v=1,409,295,000$ US\$

\begin{tabular}{|l|l|l|l|}
\hline $\mathrm{n}_{02-87}=2$, & $\mathrm{n}_{03-83}=1$, & $\mathrm{n}_{03-87}=2$, & $\mathrm{n}_{05-56}=1$, \\
\hline $\mathrm{n}_{05-58}=1$, & $\mathrm{n}_{05-68}=1$, & $\mathrm{n}_{06-67}=1$, & $\mathrm{n}_{10-11}=1$, \\
\hline $\mathrm{n}_{13-15}=3$, & $\mathrm{n}_{14-59}=1$, & $\mathrm{n}_{15-16}=3$, & $\mathrm{n}_{16-44}=3$, \\
\hline $\mathrm{n}_{16-61}=1$, & $\mathrm{n}_{18-50}=6$, & $\mathrm{n}_{18-74}=3$, & $\mathrm{n}_{21-57}=1$, \\
\hline $\mathrm{n}_{22-58}=1$, & $\mathrm{n}_{24-43}=1$, & $\mathrm{n}_{25-55}=1$, & $\mathrm{n}_{26-29}=1$, \\
\hline $\mathrm{n}_{27-53}=1$, & $\mathrm{n}_{36-46}=1$, & $\mathrm{n}_{39-86}=1$, & $\mathrm{n}_{40-45}=1$, \\
\hline $\mathrm{n}_{41-64}=2$, & $\mathrm{n}_{42-44}=1$, & $\mathrm{n}_{43-55}=1$, & $\mathrm{n}_{43-58}=1$, \\
\hline $\mathrm{n}_{48-49}=1$, & $\mathrm{n}_{49-50}=2$, & $\mathrm{n}_{52-59}=1$, & $\mathrm{n}_{56-57}=1$, \\
\hline $\mathrm{n}_{61-64}=1$, & $\mathrm{n}_{61-85}=1$, & $\mathrm{n}_{61-86}=1$, & $\mathrm{n}_{67-68}=1$, \\
\hline $\mathrm{n}_{68-69}=1$, & $\mathrm{n}_{68-83}=1$, & $\mathrm{n}_{72-73}=1$, & $\mathrm{n}_{72-83}=1$, \\
\hline $\mathrm{n}_{73-74}=1$ & & & \\
\hline
\end{tabular}

Plan P2: $v=2,612,307,000$ US\$

\begin{tabular}{|l|l|l|l|}
\hline $\mathrm{n}_{01-02}=1$, & $\mathrm{n}_{02-60}=1$, & $\mathrm{n}_{04-05}=2$, & $\mathrm{n}_{04-81}=4$, \\
\hline $\mathrm{n}_{05-56}=1$, & $\mathrm{n}_{05-58}=3$, & $\mathrm{n}_{05-60}=1$, & $\mathrm{n}_{06-67}=1$, \\
\hline $\mathrm{n}_{12-15}=1$, & $\mathrm{n}_{13-14}=1$, & $\mathrm{n}_{13-15}=4$, & $\mathrm{n}_{14-59}=1$, \\
\hline $\mathrm{n}_{15-16}=4$, & $\mathrm{n}_{15-45}=1$, & $\mathrm{n}_{15-46}=1$, & $\mathrm{n}_{16-44}=6$, \\
\hline $\mathrm{n}_{16-61}=1$, & $\mathrm{n}_{18-50}=11$, & $\mathrm{n}_{18-74}=6$, & $\mathrm{n}_{21-57}=2$, \\
\hline $\mathrm{n}_{22-58}=1$, & $\mathrm{n}_{24-43}=1$, & $\mathrm{n}_{25-55}=4$, & $\mathrm{n}_{26-54}=1$, \\
\hline $\mathrm{n}_{27-53}=1$, & $\mathrm{n}_{30-63}=2$, & $\mathrm{n}_{36-46}=1$, & $\mathrm{n}_{39-86}=2$, \\
\hline $\mathrm{n}_{40-45}=2$, & $\mathrm{n}_{41-64}=2$, & $\mathrm{n}_{42-44}=2$, & $\mathrm{n}_{43-55}=2$, \\
\hline $\mathrm{n}_{43-58}=3$, & $\mathrm{n}_{49-50}=5$, & $\mathrm{n}_{52-59}=1$, & $\mathrm{n}_{53-86}=1$, \\
\hline $\mathrm{n}_{54-63}=1$, & $\mathrm{n}_{56-57}=1$, & $\mathrm{n}_{61-64}=1$, & $\mathrm{n}_{61-85}=2$, \\
\hline $\mathrm{n}_{67-71}=1$ & $\mathrm{n}_{68-69}=1$ & $\mathrm{n}_{68-83}=2$ & $\mathrm{n}_{71-83}=1$, \\
\hline $\mathrm{n}_{72-73}=2$ & $\mathrm{n}_{72-83}=2$ & $\mathrm{n}_{73-74}=2$ & $\mathrm{n}_{81-83}=2$. \\
\hline
\end{tabular}

In Plan P1 convergence is reached after solving 102 LPs and removing one circuit in phase 2 . On the other hand, Plan P2 converges after solving 157 LPs and removing 3 circuits in phase 2 .

In the multi-stage planning, the best topology found using the modified hybrid algorithm is the following:

Stage P1: 1998-2002: $v_{1}=1,759,001,000$ US\$

\begin{tabular}{|l|l|l|l|}
\hline $\mathrm{n}_{02-87}=2$, & $\mathrm{n}_{03-83}=1$, & $\mathrm{n}_{03-87}=1$, & $\mathrm{n}_{04-81}=1$, \\
\hline $\mathrm{n}_{05-56}=1$, & $\mathrm{n}_{05-58}=1$, & $\mathrm{n}_{13-15}=3$, & $\mathrm{n}_{14-59}=1$, \\
\hline $\mathrm{n}_{15-16}=2$, & $\mathrm{n}_{16-44}=3$, & $\mathrm{n}_{16-61}=1$, & $\mathrm{n}_{18-50}=6$, \\
\hline $\mathrm{n}_{18-74}=3$, & $\mathrm{n}_{21-57}=1$, & $\mathrm{n}_{22-58}=1$, & $\mathrm{n}_{25-55}=2$, \\
\hline $\mathrm{n}_{26-54}=1$, & $\mathrm{n}_{30-63}=1$, & $\mathrm{n}_{36-46}=1$, & $\mathrm{n}_{40-45}=1$, \\
\hline $\mathrm{n}_{41-64}=2$, & $\mathrm{n}_{49-50}=3$, & $\mathrm{n}_{52-59}=1$, & $\mathrm{n}_{54-55}=1$, \\
\hline $\mathrm{n}_{54-63}=1$, & $\mathrm{n}_{54-79}=2$, & $\mathrm{n}_{56-57}=1$, & $\mathrm{n}_{61-85}=2$, \\
\hline $\mathrm{n}_{63-64}=1$, & $\mathrm{n}_{67-69}=1$, & $\mathrm{n}_{67-71}=2$, & $\mathrm{n}_{68-83}=1$, \\
\hline $\mathrm{n}_{71-72}=1$, & $\mathrm{n}_{72-73}=1$, & $\mathrm{n}_{72-83}=1$, & $\mathrm{n}_{73-74}=1$, \\
\hline $\mathrm{n}_{78-79}=1$, & $\mathrm{n}_{78-80}=1$, & $\mathrm{n}_{80-81}=1$, & $\mathrm{n}_{81-83}=1$, \\
\hline
\end{tabular}

Stage P2: 2002-2008: $v_{2}=946,200,000$ US $\$$

\begin{tabular}{|l|l|l|l|}
\hline $\mathrm{n}_{01-02}=1$, & $\mathrm{n}_{04-05}=1$, & $\mathrm{n}_{04-68}=1$, & $\mathrm{n}_{04-81}=3$, \\
\hline $\mathrm{n}_{12-15}=1$, & $\mathrm{n}_{13-14}=1$, & $\mathrm{n}_{13-15}=1$, & $\mathrm{n}_{15-16}=2$, \\
\hline $\mathrm{n}_{15-45}=1$, & $\mathrm{n}_{15-46}=1$, & $\mathrm{n}_{16-44}=3$, & $\mathrm{n}_{18-50}=5$, \\
\hline $\mathrm{n}_{18-74}=3$, & $\mathrm{n}_{21-57}=1$, & $\mathrm{n}_{22-23}=1$, & $\mathrm{n}_{22-58}=1$, \\
\hline $\mathrm{n}_{25-55}=1$, & $\mathrm{n}_{27-53}=1$, & $\mathrm{n}_{36-46}=1$, & $\mathrm{n}_{40-45}=1$, \\
\hline $\mathrm{n}_{41-64}=1$, & $\mathrm{n}_{49-50}=2$, & $\mathrm{n}_{54-55}=1$, & $\mathrm{n}_{54-63}=1$, \\
\hline $\mathrm{n}_{54-79}=1$, & $\mathrm{n}_{61-85}=1$, & $\mathrm{n}_{71-83}=1$, & $\mathrm{n}_{72-73}=1$, \\
\hline $\mathrm{n}_{73-74}=1$ & & & \\
\hline
\end{tabular}

In the multi-stage planning the algorithm converges after solving 175 LPs and removing 1 circuit from the first stage's phase 2 and 1 circuit of second stage's phase 2 . The total investment cost is $\mathrm{v}=\mathrm{US} \$ 2,405,256,000$.

\section{ANALYSIS OF THE RESULTS}

The proposed constructive heuristic algorithm for the hybrid linear model finds good quality topologies for the tested systems. Considering small or medium sized systems, the proposed CHA finds quasi-optimal solutions. However, the CHA's performance becomes less efficient when system complexity increases. It must be noticed that the critical phase occurs in the final stage when all $n_{i j} \quad \neq 0$ given by LP solution are small. In this condition, the used sensitivity criterion becomes inefficient because small $n_{i j} \quad \neq 0$ can introduce expensive circuits when path $\mathrm{i}-\mathrm{j}$ is made $\mathrm{n}_{i-j}$ $=1$. This problem was already observed for the CHA presented in Ruben et alii (2003). Getting around this problem in an adequate manner would represent a significant contribution to the CHA that uses the solution of relaxed model as a sensitivity indicator.

The topologies found by CHA present many attractions for the present context of the transmission system planning: (1) The proposed solutions become closer to DC model's optimal or sub-optimal solutions and consequently, present less load shedding than HLM's optimal solution, (2) these solutions can be used as bounds in branch-and-bound algorithms to find HLM's optimal solution, and (3) the topologies can be used for generating high quality initial topologies for meta-heuristic methods such as the genetic algorithm, or elite topologies for tabu-search algorithm (Da Silva et alii, 2000 and 2001; Gallego et alii, 2000). Additionally, a detailed bibliography on the planning problem can be found in Latorre et alii (2003).

\section{CONCLUSIONS}

This paper presented one version of constructive heuristic algorithm (CHA) for the hybrid linear model (HLM). The proposed algorithm was extended to the multi-stage planning, where excellent results were presented. The tests showed an 
efficient performance of the algorithm and also the pitfalls that can occur with this kind of algorithms. The version presented itself as fast and robust. Finally, it is important to observe that beside its conventional use in the transmission network synthesis, the CHA is specially suited for generating good quality initial topologies for evolutive algorithms or elite topologies in a tabu meta-heuristic search. Another application is the generation of excellent bounds for branchand-bound algorithms.

\section{REFERENCES}

Da Silva, E.L., H.A. Gil and J.M. Areiza (2000). Transmission network expansion planning under an improved genetic algorithm. IEEE Transaction on Power Systems, Vol. 4, 15, pp. 1168-1175.

Da Silva, E.L., J.M. AREIZA, G.C. De Oliveira and S. Binato (2001). Transmission network expansion planning under a tabu search approach. IEEE Transaction on Power Systems, Vol. 1, 16, pp. 62-68.

Dechamps, C. and A. Jamoulle (1980). Interactive computer program for planning the expansion of meshed transmission networks. International Journal of Electrical Power and Energy Systems, Vol. 2, 2, pp. 103-108.

Gallego, R.A., A. Monticelli and R. Romero (1998). Comparative studies of non-convex optimization methods for transmission network expansion planning. IEEE Transactions on Power Systems, Vol. 3, 13, pp. 822828.

Gallego, R.A., A. Monticelli and R. Romero (2000). Tabu search algorithm for network synthesis. IEEE Transaction on Power Systems, Vol. 2, 15, pp. 490-495.

Garver, L.L (1970). Transmission network estimation using linear programming. IEEE Trans. Power App. Syst., 89, pp. $1688-1697$.

Haffner, S., A. Monticelli, A. Garcia and R. Romero (2001). Specialized branch and bound algorithm for transmission network expansion planning. IEE Proceedings Generation, Transmission and Distribution, Vol. 5, 148, pp. 482-488.

Latorre, G., R.D. Cruz, J.M. Areiza and A. Villegas (2003). Classification of publications and models on transmission expansion planning. IEEE Transaction on Power Systems, Vol. 2, 18, pp. 938-946.

Levi, V.A. and M.S. Calovic (1991). A New decomposition based method for optimal expansion planning of large transmission network. IEEE Transaction on Power Systems, Vol. 3, 6, pp. 937-943.
Monticelli, A., A. Jr. Santos, M.V.F. PEREIRA, S.H. Cunha, B.J. Parker, J.C.G. Praça (1982). Interactive transmission network planning using a least-effort criterion. IEEE Trans. Power App. System, Vol. 10, 101, pp. 3919-3925.

Pereira, M.V.F. and L.M.V.G. Pinto (1985). Application of sensitivity analysis of load supplying capability to interactive transmission expansion planning. IEEE Transaction on Power Apparatus and Systems, Vol. 2, 104, pp. 381-389.

Romero, R., A. Monticelli, A. GARCIA, and S.Haffner (2002). Test systems and mathematical models for transmission network expansion planning. IEE Proceedings - Generation, Transmission and Distribution, Vol. 1, 149, pp. 27-36.

Romero, R., C. Rocha, M. Mantovani and J.R.S Mantovani (2003). Analysis of heuristic algorithms for the transportation model in static and multi-stage planning in network expansion systems. IEE Proceedings - Generation, Transmission and Distribution, Vol. 5, 150, pp. 521-526.

Villasana, R., L.L. Garver and S.J. Salon (1985). Transmission network planning using linear programmimg. IEEE Trans. Power App. Systems, Vol. 2, 104, pp. 349356. 